\title{
INFOGRAPHIC SILSILAH SULTAN YANG PERNAH MEMERINTAH DI KESULTANAN DELI
}

\author{
Infographic Genealogical Sultan Who ever ruled in Kesultanan Deli
}

\author{
Rinanda Purba*1, Irwansyah ${ }^{2}$ \\ ${ }^{1}$ Desain Komunikasi Visual Fakultas Seni dan Desain Universitas Potensi Utama \\ ${ }^{2}$ Desain Interior Fakultas Seni dan Desain Universitas Potensi Utama \\ E-mail: *1 azul.creator@gmail.com, ${ }^{2}$ irw.syah23@gmail.com
}

\begin{abstract}
ABSTRAK
Kesultanan Deli adalah salah satu dari empat Kesultanan Besar yang ada di Sumatera Utara. Nama Deli sendiri diambil dari sejarah Raja Deli I yakni Tuanku Gotjah Pahlawan yang merupakan keturunan dari Raja Delhi Akbar (Hindusta, India). Deli merupakan sebuah kerajaan dengan konsep Kesultanan, dimana pewarisan tahta akan dilanjutkan oleh keturunan laki-laki dari Sultan sebelumnya. ini dirasa penting untuk dipecahkan dan diberikan solusi dengan membuat sebuah buku infographic wisata sejarah Sultan-Sultan yang pernah memerintah di Kesultanan Deli. Tujuannya dapat digunakan oleh wisatawan dan masyarakat untuk lebih mengenal dengan baik dan mengetahui informasi tentang Sultan yang pernah memerintah di Kesultanan Deli dari Sultan pertama hingga Sultan saat ini. Dalam melakukan analisis penelitian ini menggunakan Teknik analisis $5 \mathrm{~W}+1 \mathrm{H}$. Dengan menggunakan media infographic lebih menarik dan kreatif agar dapat menarik minat masyarakat sehingga dapat dijadikan media promosi untuk memperkenalkan sejarah Istana Maimoon.
\end{abstract}

Kata Kunci : Deli, Infografik dan Istana Maimoon

\begin{abstract}
The Deli Sultanate is one of the four Great Sultanates in North Sumatra. The name Deli itself is taken from the history of the Deli I King, Tuanku Gotjah Pahlawan who is a descendant of the King of Delhi Akbar (Hindusta, India). Deli is a kingdom with the concept of the Sultanate, where the inheritance of the throne will be continued by male descendants from the previous Sultan. this is considered important to be solved and given a solution by making an infographic book on the history of the Sultan's Sultan who had ruled in the Sultanate of Deli. The goal can be used by tourists and the public to get to know better and find out information about the Sultan who once ruled in the Sultanate of Deli from the first Sultan to the current Sultan. In conducting the analysis of this study using $5 W+1 H$ analysis techniques. By using infographic media more interesting and creative in order to attract public interest so that it can be used as promotional media to introduce the history of Maimoon Palace.
\end{abstract}

Keywords: Deli, Infographic dan Istana Maimoon

\section{PENDAHULUAN}

Tinggal di suatu daerah dengan jangka waktu yang cukup lama, tentunya akan melahirkan kecintaan terhadap daerah tersebut. Namun kecintaan tersebut tidak dapat dijadikan tolak ukur apakah seorang individu mengenal dengan baik dan mengetahui 
informasi yang tepat mengenai daerah yang telah lama ditempatinya. Oleh sebab itu diperlukan adanya pengelolaan dan penyampaian informasi secara baik dan menarik oleh pengelola daerah agar individu ataupun masyarakat mengetahui informasi dan mengenal daerah yang ditempatinya dengan baik dan akurat. Salah satu contohnya adalah sejarah tentang silsilah Sultan Deli yang pernah memerintah di Kesultanan Deli.

Deli merupakan sebuah kerajaan dengan konsep Kesultanan, dimana pewarisan tahta akan dilanjutkan oleh keturunan laki-laki dari Sultan sebelumnya. Sultan Deli yang pertama adalah Tuanku Panglima Gocah Pahlawan dan Sultan yang saat ini yaitu Sultan Mahmud Lamanjiji Perkasa Alam. Sampai saat ini telah tercatat 14 generasi yang telah dan sedang memegang gelar sebagai Sultan Deli.

Informasi mengenai silsilah Sultan Deli dari generasi ke generasi bisa ditemui di Istana Maimun yang berada di Kota Medan. Penyajian informasi tersebut berupa deretan fotofoto beserta keterangan nama Sultan yang pernah memerintah di Kesultanan Deli. Pengunjung Istana dapat melihat informasi tersebut di dinding bagian dalam Istana Maimun.

Penyajian informasi seperti yang telah disebutkan sebelumnya ternyata dirasa kurang menarik bagi pengunjung dan masyarakat. Kondisi ini dapat menyebabkan memudarnya rasa penghormatan kepada para Sultan terdahulu yang telah meninggalkan warisan berupa kebudayaan dan peradaban yang saat ini kita nikmati. Sebagai cagar wisata budaya, penyajian informasi mengenai silsilah Sultan Deli ini dapat disajikan dengan media yang lebih menarik agar dapat meningkatkan minat dan antusiasme pengunjung dan masyarakat dalam mengenal dan mengenang generasi Sultan Deli.

Dengan berkembangnya zaman dan cara berkomunikasi yang telah mengalami evolusi, maka muncul kesempatan untuk membuat media yang lebih kreatif dengan menggunakan media tulisan dan gambar visual sehingga menambah daya tarik terhadap sebuah informasi. Perancangan media tersebut diharapkan mampu menyelesaikan masalah yang selama ini dialami individu dan masyarakat sekitar lingkungan Kesultanan Melayu Deli. Media tersebut adalah infografik sejarah Sultan-Sultan yang pernah memerintah di Kesultanan Deli.

Untuk mendapatkan petunjuk yang jelas dari suatu tempat atau benda adalah dengan adanya suatu informasi. Jadi dengan adanya sebuah informasi yang lengkap dapat mendukun dan meningkatkan perkembangan suatu objek wisata sejarah. Dengan adanya sebuah buku informasi tentang objek wisata sejarah bukan hanya sebagai suatu pemberian informasi saja tetapi dapat juga dijadikan sebagai sebuah sarana untuk melakukan promosi dari objek wisata sejarah tersebut. Untuk mendapatkan informasi yang lengkap, buku tentang objek wisata ini baik jikalau disediakan pada setiap objek wisata. Untuk menarik minat wisatawan maka sebuah informasi yang diberikan pada buku panduan pada objek wisata tidaklah hanya berupa informasi saja tetapi harus dikemas dengan dengan bentuk yang menarik sehingga membuat para wisatawan ingin membaca dan memilikinya serta akan menimbulkan rasa ingin mengunjungi objek wisata sejarah oleh para wisatawan. Dengan begitu adanya buku panduan tentang objek wisata sejarah sebagai sebuah sarana untuk promosi akan tercapai.

Permasalahan ini dirasa penting untuk dipecahkan dan diberikan solusi dengan membuat sebuah buku infographic wisata sejarah Sultan-Sultan yang pernah memerintah di Kesultanan Deli. Tujuannya dapat digunakan oleh wisatawan dan masyarakat untuk lebih mengenal dengan baik dan mengetahui informasi tentang Sultan yang pernah memerintah di Kesultanan Deli dari Sultan pertama hingga Sultan saat ini.

Untuk mendalami semua informasi yang terkait dalam pengembangan penyajian informasi. Pengembangan penelitian ini berupa pembuatan media infographic silsilah sultan deli. Penelitian pengembangan dilakukan dengan mengadakan investgasi formal, 
mengumpulkan data (informasi), melakukan tabulasi dan analisis data, pembuatan media infographic dan menarik kesimpulan serta saran. Untuk mendapatkan informasi terkait silsilah sultan yang pernah memerintah di kesultanan deli, maka perlu adanya sebuah analisis data. Penganalisis ini dilakukan dengan teknik analisis $5 \mathrm{~W}+1 \mathrm{H}$ untuk mendapatkan konsep yang sesuai dengan perancangan.

1) What (Apa)

Peninggalan kesultanan Deli, informasi tentang adanya sejarah singkat, serta informasi silsilah dari sultan Deli tersebut yang dikemas ke dalah sebuah buku panduan atau buku inforgrafis.

2) Who (Siapa) ini.

Silsilah sultan Deli adalah objek utama yang menjadi focus perancangan infografis

3) Where (Dimana)

Istana Maimoon Medan yang berada di Jl. Brigjen Katamso Kelurahan Sukaraja Kecamatan Medan Maimoon, Medan.

4) When (Kapan)

Untuk menemukan sebuah informasi lengkap, data yang diperoleh dari tahun 1632 sebelum Masehi sampai dengan perancangan infographic iini dibuat.

5) Why (Mengapa)

Objek perancangan dalam penelitian ini tentang silsilah sultan yang pernah memerintah dikesultanan deli, dimana tidak ada buku yang dapat memberikan informasi tentang silsilah kesultanan deli ini.

6) How (Bagaimana)

Membuat rancangan buku infografis yang berisikan sejarah singkat yang dikemas semanarik mungkin sehingga dapat dipahami oleh masarakat terutama bagi kalangan remaja agar tahu akan sejarah. Langkah dalam perancangan dimulai dengan melakukan penelusuran data baik secara langsung dengan mengunjungi lokasi atau tidak langsung dengan menumpulkan beberapa buku, artikel ilmiah dan lain-lainnya. Kemudian dengan melakukan observasi lapangan untuk mendapatkan permasalahan, yang selanjutnya melakukan perancangan informasi ke dalam bentuk sebuah buku infografik.

\subsection{Infografis}

Infografis berasal dari kata Infographics dalam Bahasa Inggris yang merupakan singkatan dari Information + Graphics adalah bentuk visualisasi data yang menyampaikan informasi kompleks kepada pembaca agar dapat dipahami dengan lebih mudah dan cepat. Infografis berasal dari kata informasi yang digabungkan dengan grafis. Maknanya pun tidak lain adalah representasi grafis dari informasi. Pada kenyataannya, dalam membuat sebuah infografis seorang perancang perlu memiliki kemampuan dan pengetahuan desain grafis (Inigopatria, $2014: 12$ ).

Infografis menyediakan sebuah format yang memanfaatkan cara-cara visual yang tidak hanya memikat audiens yang haus informasi, tetapi juga membantu mereka dalam menghayati dan mempertahankan informasi tersebut (Lankow, Ritchie, Crooks, 2014 : 12). Infografis dicirikan dengan ilustrasi, tipografi besar, dan orientasi memanjang vertical yang menampilkan berbagai informasi atau fakta.

Infografis mencakup presentasi visual yang dapat menjelaskan rangkaian cerita atau proses dari serangkaian data dengan menggunakan berbagai elemen seperti gambar, ilustrasi, tipografi, peta dan visualisasi (Dur, 2014). Lebih lanjut Krum menyebutkan bahwa visualisasi data tidak dapat secara lengkap menunjukkan infografis, tetapi merupakan alat yang biasa digunakan oleh perancang dalam membantu memvisualisasikan cerita dalam sebuah infografis (Krum, 2013). Desain grafis memiliki kekuatan dalam 
menjelaskan tujuan dan data yang ada, sedangkan visualisasi data menekankan pada estetika dengan mengadopsi prinsip desain grafis. Pertemuan diantara keduanya membuat data lebih bermakna, berwawasan dan berpengaruh.

Perlu dipahami bahwa: Infographic adalah teknik menyajikan informasi secara visual/grafis, sehingga mudah dipahami oleh pembaca. Banyak orang salah mengartikan dengan menyebut kata infografik adalah karena pada infografis sering terlihat ada grafik (chart) apapun itu grafik batang/pie chart. Padahal infographic sendiri itu masih sangat luas daripada hanya sekedar chart. Kemungkinan lainnya adalah orang menyebutkan kata infographic (dalam Bahasa Inggris) secara lisan, lalu terdengar sebagai Infografik dalam Bahasa Indonesia.

Menurut Smiciklas (2012 : 5) Penting untuk dipahami bahwa Infografis tidak digunakan semata-mata untuk berkomunikasi. Infografis adalah media yang baik untuk menyampaikan pesan pemasaran atau wawasan kepada konsumen dan prospek, tapi mereka sama-sama efektif bila digunakan untuk meningkatkan komunikasi internal.

Adapun tujuan dibuatnya infografis adalah :

1. Untuk mengkomunikasikan pesan yang kompleks menjadi lebih sederhana.

2. Dapat mempresentasikan informasi lebih singkat dan mudah dipahami.

3. Dapat menjelaskan data lebih mudah.

4. Dapat memonitor secara periodik setiap parameter perubahan.

Menurut Krum, tujuan infografis adalah sama dengan public speaking Tujuan dari infografis dapat dibagi menjadi tiga kategori yaitu untuk menginformasikan, menghibur dan mempersuasi audiens sehingga audiens memberikan perhatian, menyempatkan untuk membaca, menyimpulkan dan melakukan aksi sesuai apa yang ada di dalam infografis (Krum, 2013).

Jenis-jenis infografis yang dapat digunakan sebagai media penyampaian komunikasi infografis yaitu :

a. Infografis Statis

Infografis statis adalah infografis yang ditampilkan dalam format diam atau gambar mati dan biasanya berupa informasi tetap. Interaksi pengguna mencakup melihat dan membaca. Infografis statis menampilkan citra/grafis diam (Lankow, Ritchie, Crooks, 2014 : 59). Infografis statis banyak digunakan dalam editorial berita media cetak. Salah satu manfaat utama dalam konten statis adalah relatif mudahnya dalam membuat citra statis dibanding sebuah antarmuka interaktif.

b. Infografis Bergerak

Selain dalam bentuk statis, infografis juga dapat disampaikan dalam bentuk yang bergerak (motion). Infografis bergerak menyampaikan informasi secara bertahap dalam satu konten infografis. Biasanya infografis bergerak disampaikan dalam format audio visual yang didalamnya terdapat informasi yang disampaikan dan juga terdapat suara latar belakang, sehingga audiens dapat duduk dan menikmati narasi yang disajikan dalam bentuk linier (Lankow, Ritchie, Crooks, 2014 : 74).

Perbedaan mendasar yang antara konten infografis bergerak dan statis adalah waktu. Menurut definisi, konten statis tidak berubah sejalan dengan waktu, kandungan visualnya juga tidak berubah. Sebaliknya, konten bergerak berubah sejalan dengan waktu.

c. Infografis Interaktif

Infografis Interaktif berisi tentang informasi yang akan disampaikan dalam jumlah yang banyak, sehingga dalam format ini merupakan gabungan antara infografis statis dan infografis bergerak. Dalam penggunaannya, audiens hanya tinggal melihat informasi yang disampaikan dalam suatu scene yang di dalamnya terdapat bebagai 
informasi, dan apabila audiens tersebut menginginkan informasi yang lebih lanjut dapat melakukan pemilihan sendiri dalam konten infografis yang telah disediakan.

\subsection{Kesultanan Deli}

Kesultanan Deli adalah salah satu dari empat Kesultanan Besar yang ada di Sumatera Utara. Nama Deli sendiri diambil dari sejarah Raja Deli I yakni Tuanku Gotjah Pahlawan yang merupakan keturunan dari Raja Delhi Akbar (Hindusta, India). Wilayah Kesultanan Deli dibagi atas empat wilayah besar dimana setiap wilayah dipimpin oleh Kepala Urung.

a. Kepala Urung XII Kuta (Sepuluh Dua Kuta)

Wilayahnya mencakup Hamparan Perak, Tandem, dan Buluh Cina

b. Kepala Urung Serbanyaman

Wilayahnya mencakup Sunggal, Helvetia dan Diski.

c. Kepala Urung Sukapiring

Wilayahnya mencakup sebagian wilayah Kota Medan

d. Kepala Urung Senembah Deli

Wilayahnya mencakup Deli Tua sampai ke Tanjung Morawa.

Selain itu juga ada tiga wilayah yang dikepalai oleh kerabat Sultan, yaitu:

a. Percut yang dikepalai oleh Kejuruan Paduka Raja Percut

b. Padang (Tebing Tinggi) yang dikepalai oleh Maharaja Bedagai

c. Bedagai yang dikepalai oleh Pangeran Nara Kelana Begadai

Empat kepala Urung ini serta tiga wilayah yang disebutkan, memiliki peran besar didalam Kesultanan Deli. Sultan juga menempatkan kepala-kepala kampung atau yang ketika dahulu disebut "Penghulu" untuk wilayah Tanah Karo dan sekitarnya. Disepanjang sejarah keberadaanya, Kerajaan Deli sudah sejak awal abad ke-17 hingga pertengahan abad ke-20 M sampai ketika memutuskan bergabung dengan Negara Kesatuan Republik Indonesia. Sampai saat ini Kesultanan Deli masih eksis sebagai sebuah Kesultanan dimana Sultan-nya bertindak sebagai Kepala Adat dan Adat Istiadatnya masih tetap dilaksanakan sebagai cermin dari budaya bangsa yang luhur.

Kesultanan Deli adalah sebuah Kesultanan yang didirikan pada tahun 1632 oleh Tuanku Panglima Gocah Pahlawan di wilayah bernama Tanah Deli. Sejarah berdirinya Kesultanan Deli dapat dilihat dari Hikayat Deli, seorang pemuka Aceh bernama Muhammad Dalik berhasil menjadi laksamana dalam Kesultanan Aceh. Muhammad Dalik, yang kemudian juga dikenal sebagai Gocah Pahlawan dan bergelar Laksamana Khuja Bintan (ada pula sumber yang mengeja Laksamana Kuda Bintan), adalah keturunan dari Amir Muhammad Badar ud-din Khan, seorang bangsawan dari Delhi, India yang menikahi Putri Chandra Dewi, putri Sultan Samudera Pasai. Dia dipercaya Sultan Aceh untuk menjadi wakil bekas wilayah Kerajaan Haru yang berpusat di daerah Sungai LalangPercut. Sultan Gocah menikahi adik dari Raja Urung (negeri) Sunggal yaitu Puteri Nang Baluan Beru Surbakti. Sunggal adalah daerah yang merupakan Batak Karo yang sudah bercampur dengan Melayu (Islam). Dari kerajaan Urang Sunggal tersebut Sultan Gocah dianggat menjadi raja Deli di tahun 1630 M dan beliau menjadi Sultan Pertama di Kesultanan Deli.

Pemegang kekuasaan selanjutnya dipegang oleh putra Mahkota atau anak dari sultan. Sultan Deli saat ini dijabat oleh Tuanku Mahmud Lamantjiji Perkasa Alam, beliau sultan Deli ke XIV. Beliau diangkat menjadi sultan pada tahun 2005 saat berusia tujuh tahun menggantikan ayahnya Tuanku Otteman Mahmud Paderap Perkasa Alam. Tuanku Otteman Mahmud yaitu sultan Deli ke XIII meninggal pada kecelakaan pesawat di Aceh 
tahun 2005 dalam usia 39 tahun. Beliau adalah prajurit TNI menjabat Komandan Batalyon Siliwangi. Sesuai adat maka kesultanan digantikan oleh anaknya Tuanku Mahmud Lamantjiji Perkasa Alam.

\section{STUDI LITERATUR}

Infografis adalah suatu representasi visual dari sebuah obyek, dan data. Sebuah Bahasa verbal akan lebih mudah dipahami jika dirancang secara singkat dan jelas jikalau dirancang dengan Bahasa visual atau dengan penggunaan gambar sebagai medianya. Dengan penyajian informasi tentang silsilah sultan yang pernah memerintah di Kesultanan Deli seperti ini akan membuat lebih mudah dipahami dan menarik banyak orang untuk lebih mengetahui tentang sejarah Kesultanan Deli.

Untuk melakukan perancangan infographic silsilah sultan Deli, peneliti menggunakan beberapa penelitian yang terkait dengan penelitian ini sebagai acuan atau pijakan. Yang pertama oleh Setiawan Agus Prasetya (2017) dengan "Perancangan Buku infografis kompleks masjid Gedhe Mataram Kotagede", Setiawan mengatakan dalam penelitiannya sebuah rancangan sebuh buku dengan media infografik lebih mudah dirasakan dan dipahamai oleh remaja masa kini, sehingga buku yang dirancang akan sesuai dengan target audiens. Kedua dari penelitian Ajeng Resnatika, Sukaesih, Nuning Kurniasih (2018) yang berjudul "Peran infografis sebagai media promosi dalam pemanfaatan perpustakaan”, dalam penelitiannya ini dikatakan bahwa peran infografis sebagai media promosi dalam pemanfaatan perpustakaan dilihat dari aspek kemudahan dipahami dapat disimpulkan bahwa pesan informasi yang terdapat pada infografis mudah dipahami oleh pembacanya. Menggunakan infografis untuk memasarkan konten karena kemudahan dan kecepatan yang dimungkinkan dalam komunikasi.

\section{PEMBAHASAN}

Istana maimoon adalah salah satu kerajaan yang ada di Sumatera Utara yang sangat indah diantara sekian banyak Istana yang ada di Indonesia. Istana maimoon adalah Kerajaan Deli yang dipimpin oleh Sultan, dimana Sultan yang dimaksud seorang yang memegang kekuasaan dan yang menjalankan tugas serta wewenangnya dalam melakukan pemerintahan. Sultan juga sebagai pemimpin dalam melakukan adat dan istiadat yang dijalankan dikerajaan tersebut. Istana maimoon memiliki bangunan yang berdiri diatas tanah $2.772 \mathrm{~m} 2$ dengan diminasi warna Istana adalah kuni keemas an yang merupakan identitas warna yang khas Melayu.

Istana maimoon sejak pada tahun 1946 hingga saat sekarang dihuni oleh para keturanan atau ahli waris dari Kesultanan Deli tersebut. Istana maimoon ini selalu mengadakan berbagai kegiatan misalnya kegiatan pertunjukan music tradisional budaya setempat yaitu Melayu. Kegiatan tahunan yang diadakan di Istana Maimoon juga menjadi salah satu agenda kegiatan rutin yang dilaksankan oleh keluarga Sultan Deli yaitu melakukan silaturahmi antar keluar besar istana.

Deli merupakan sebuah kerajaan dengan konsep Kesultanan, dimana pewarisan tahta akan dilanjutkan oleh keturunan laki-laki dari Sultan sebelumnya. Sultan Deli yang pertama adalah Tuanku Panglima Gocah Pahlawan dan Sultan yang saat ini yaitu Sultan Mahmud Lamanjiji Perkasa Alam. Sampai saat ini telah tercatat 14 generasi yang telah dan sedang memegang gelar sebagai Sultan Deli. 
Informasi mengenai generasi Sultan yang pernah memerintah di Kesultanan Deli saat ini masih terbatas pada deretan foto yang terletak pada dinding bagian dalam Istana Maimun. Kondisi ini menyebabkan kurang tersampaikannya informasi kepada wisatawan dan masyarakat. Untuk itu perlu dicari solusi dalam penyajian informasi mengenai Silsilah Sultan yang pernah memerintah di Kesultanan Deli dengan cara yang lebih menarik dan kreatif agar dapat menarik minat wisatawan dan masarakat. Salah satu media penyajian kreatif dan informative adalah dengan menggunakan media infographic. Berikut nama-nama sultan Deli yang pernah memerintah kesultanan Deli:

1. Tuanku Panglima Gocah Pahlawan (1632-1669)

Tuanku Panglima Gocah Pahlawan adalah salah satu Putra keturunan Rana Hindustan yang Bernama Muhammad Dalik atau sering dikenal dengan nama Muhammad Delikhan. Beliau diberi nama Tuanku Panglima Gocah Pahlawan oleh Sultan Iskandar Muda setelah menerima ujian keberanian dan kegagahannya dengan bertitah agar Muhammad Dalik dapat mengalahkan seekor Gajah yang bernama Gandasuli. Alangkah takjubnya Sultan Iskandar Muda ketika melihat Muhammad Dalik mengalakan Gajah yang mengamuk tersebut dengan mudah dan sekejab. Pada tahun 1632 Tuanku Panglima Gocah Pahlawan dirajakan di Deli oleh datuk-datuk kepala urang yang tinggal didaerah Sunggal, yang dimana Tanah Deli adalah daerah kekuasaan Kerajaan Aru yang ditaklukkan oleh Aceh. Berikut diilustrasikan sebuah gambar Tuanku Panglima Gocah Pahlawan karena tidak adanya gambar dan/ataupun bukti wajah Tuanku Panglima Gocah Pahlawan di Istana Maimoon.

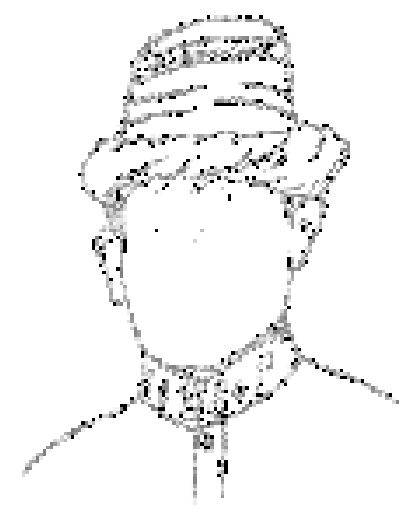

Gambar 1. Sultan ke I : Tuanku Panglima Gocah Pahlawan (1632-1669)

2. Tuanku Panglima Parunggit (1669-1698)

Tuanku Panglima Parunggit adalah Raja Deli yang ke II, dimana Tuanku Panglima Parunggit yang melakukan pemindahan pusat kerajaan ke daerah padang datar (Kota Medan sekarang). Tuanku Panglima Parunggit menikah dengan Nang Baluan anak Datuk Sunggal yang pada saat itu berkuasa atas wilayah Karo. Oleh sebab pernikahan itu maka Tuanku Panglima Parunggit mendapatkan gelar adat Karo yaitu "Sembiring" yang mana seterusnya menjadi gelar adat bagi keturunan-keturunannya sampai sekarang. Tuanku Panglima Parunggit mangkat pada tahun 1698 dan diberi gelar Marhum Kesawan. Sama halnya dengan Tuanku Panglima Gocah Pahlawan karena tidak adanya gambar dan/ataupun bukti wajah Tuanku Panglima Gocah Pahlawan di Istana Maimoon maka diilustrasikan sebuah gambar. 


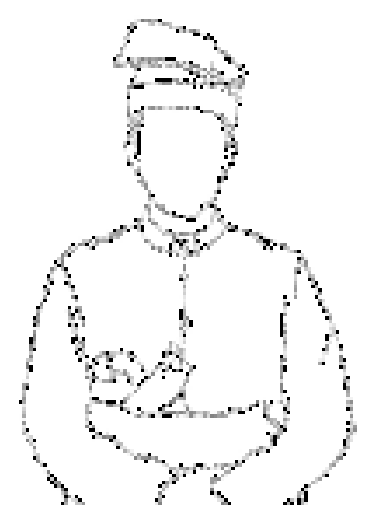

Gambar 2. Sultan ke II : Tuanku Panglima Parunggit (1669-1698)

3. Tuanku Panglima Padrap (1698-1728)

Tuanku Panglima Padrap dilahirkan pada tahun 1658 mulai melakukan pemerintahan sejak hari kemangkatan ayahandanya pada tahun 1698. Tuanku Panglima Padrap juga melakukan pemindahan ibukota Kerajaan dari Padang Datar ke Pulo Brayan. Tuanku Panglima Padrap mangkat pada tahun 1728 dan dimakamkan di Pulo Brayan. Sama halnya dengan Tuanku Panglima Gocah Pahlawan dan Tuanku Panglima Gocah Pahlawan karena tidak adanya gambar dan/ataupun bukti wajah Tuanku Panglima Padrap di Istana Maimoon maka diilustrasikan sebuah gambar.

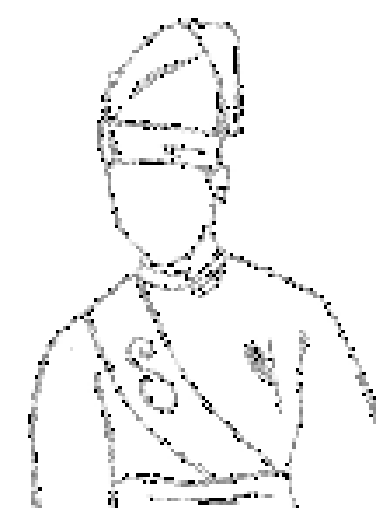

Gambar 3. Sultan ke III : Tuanku Panglima Padrap (1698-1728)

4. Tuanku Panglima Pasutan (1728-1761)

Tuanku Panglima Pasutan adalah Sultan ke IV yang mempunyai gelar Kejuruan Padang. Tuanku Panglima Pasutan menggantikan ayahnya yang mangkat tahun 1728 . Pengangkatan Tuanku Panglima Pasutan menjadi konflik sehingga terjadinya perpecahan yang mengakibatkan wilayah kekuasaan Deli terpisah yang terakhir menjadi Kesutanan Deli. Tuanku Panglima Pasutan mangkat pada tahun 1761 yang kemudian dimakamkan di pemakaman para sultan Deli yang terletak disebelah Masjid Raya Al-Osmani. Sama halnya dengan sultan pendahulu-nya, karena tidak adanya gambar dan/ataupun bukti wajah Tuanku Panglima Pasutan di Istana Maimoon sehingga diilustrasikan sebuah gambar. 


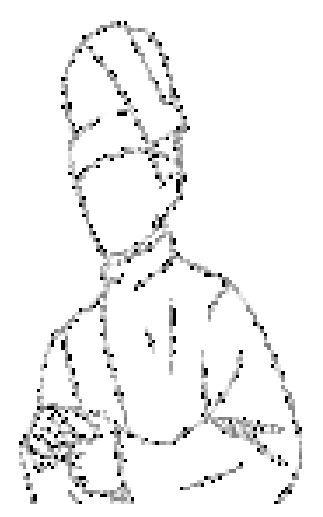

Gambar 4. Sultan ke IV : Tuanku Panglima Pasutan (1728-1761)

5. Tuanku Panglima Gandar Wahid (1761-1805)

Tuanku Panglima Gandar Wahid menjadi Raja Deli ke V. Kedudukan Datuk dibawah pemerintahan Tuanku Panglima Gandar Wahid semakin kuat dan kokoh dikarnakan peranan Datuk Empat Suku semakin terlihat nyata sebagai tim pengamanan bagi rakyat. Tuanku Panglima Gandar Wahid mangkat pada tahun 1805 yang kemudian kepemimpinan digantikan oleh Putra-nya. Sama halnya dengan sultan pendahulu-nya, karena tidak adanya gambar dan/ataupun bukti wajah Tuanku Panglima Gandar Wahid di Istana Maimoon sehingga diilustrasikan sebuah gambar.



Gambar 5. Sultan ke V : Tuanku Panglima Gandar Wahid (1761-1805)

6. Sultan Amaluddin Mangendar (1805-1850)

Sultan Amaluddin Mangendar merupakan putra ke tiga dari Tuanku Panglima Gandar Wahid, dimana Sultan Amaluddin Mangendar diangkat menjadi Sultan Ke VI setelah ayahnya mangkat pada tahun 1805 . Hubungan Kerajaan Siak pada masa pemerintahan Sultan Amaluddin Mangendar semakin kuat, sehingga adanya pemberian gelar Sultan ke Raja Deli. Dengan gelar Sultan yang diberikan oleh Kesultanan Siak ke Sultan Amaluddin Mangendar Alam yang menjadikannya Raja Deli yang pertama dalam menggunakan gelar Sultan. Sama halnya dengan sultan pendahulu-nya, karena tidak adanya gambar dan/ataupun bukti wajah Sultan Amaluddin Mangendar Alam di Istana Maimoon sehingga diilustrasikan sebuah gambar. 


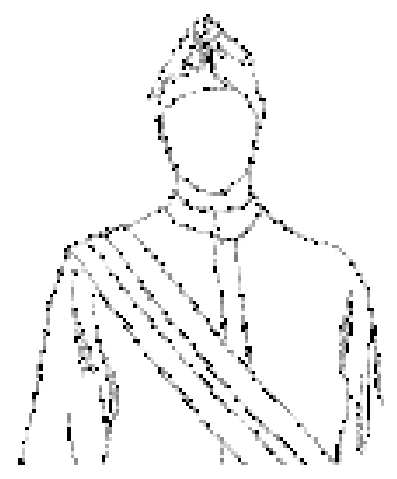

Gambar 6. Sultan ke VI : Sultan Amaluddin Mangendar (1805-1850)

7. Sultan Osman Perkasa Alam Shah (1850-1858)

Sultan Osman Perkasa Alam Shah adalah Raja Deli ke VII, dimana pada massa pemerintahan Sultan Osman Perkasa Alam Shah, Kesultanan Deli dinyatakan Kerajaan Deli yang berdiri sendiri dan dengan adanya penyerahan Pedang (Syamsir) Bawar dan Cap Sembilan (MOHOR) hal tersebut disahkan dan diberikan oleh Kerajaan Aceh. Sama halnya dengan sultan pendahulu-nya, karena tidak adanya gambar dan/ataupun bukti wajah Sultan Osman Perkasa Alam Shah di Istana Maimoon sehingga diilustrasikan sebuah gambar.

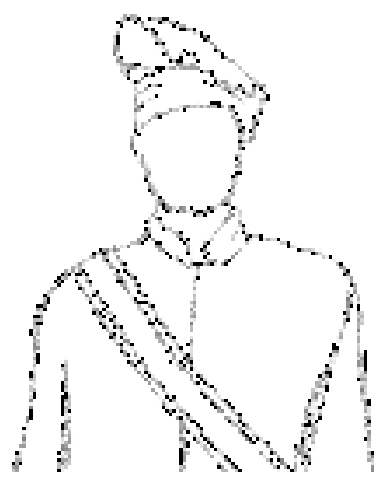

Gambar 7. Sultan ke VII : Sultan Osman Perkasa Alam Shah (1850-1858)

8. Sultan Mahmud Al Rasyid (1858-1873)

Sultan Mahmud Al Rasyid merupakan Putra pertama Sultan Osman Perkasa Alam Shah. Sultan Osman Perkasa Alam Shah diangkat menjadi Raja Kesultanan Deli yang Ke-8. Dibawah kepemimpinan Sultan Mahmud Al Rasyid, Kesultanan Deli menjadi Makmur dan banyak dikunjungi oleh berbagai bangsa. Kemakmuran yang dihasilkan dari hasil perkebunan tembakau yang bekerjasama dengan seorang pengusaha tembakau bernama Jakobus Nienhuys. Sultan Mahmud Al Rasyid mangkat pada tahun 1873 dengan usia 44 tahun. 


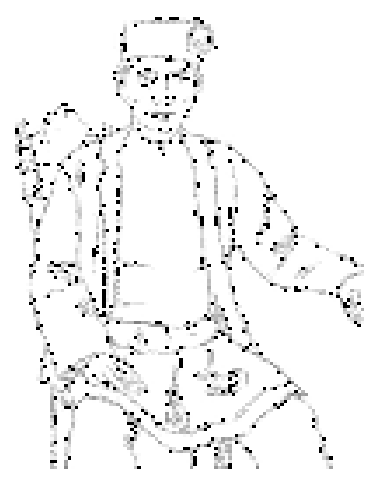

Gambar 8. Sultan ke VIII : Sultan Mahmud Al Rasyid (1858-1873)

9. Sultan Ma'moen Al Rasyid (1873-1924)

Sultan Ma'moen Al Rasyid adalah Raja Kesultanan Deli yang ke IX. Di massa pemerintahanya Sultan Ma'moen Al Rasyid melakukan pembentukan pemangku Raja dikarenakan pada massa pengangkatan Sultan Ma'moen Al Rasyid masih berusia muda.

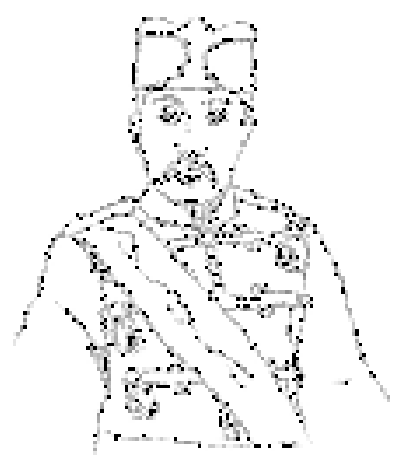

Gambar 9. Sultan ke IX : Sultan Ma'moen Al Rasyid (1873-1924)

10. Sultan Osman Al Sani Perkasa Alamsyah (1945-1967)

Sultan Osman Al-Sani Perkasa Alamsyah adalah Raja Kesultanan Deli yang ke X. Sultan Osman Al Sani Perkasa Alamsyah pernah melakukan Pendidikan di Betawi. Kemudian pada tahun 1924 Dia dititah oleh Paduka Ayahandanya Sultan Amaluddin Sani Perkasa Alamsyah untuk bekerja di pejabat (Kantor) Tuanku Sultan. Sultan Osman Al-Sani Perkasa Alamsyah memerintah antara 1945-1967. Gelar setelah mangkat adalah Marhom Tawakkallah.

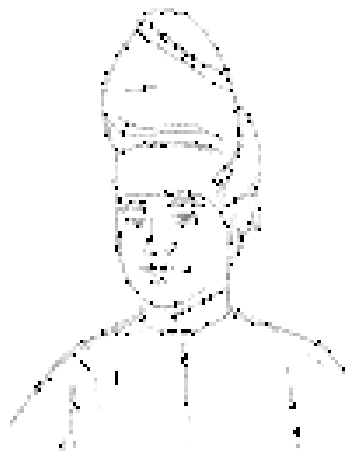

Gambar 10. Sultan ke X : Sultan Osman Al Sani Perkasa Alamsyah (1945-1967) 
11. Sultan Azmy Perkasa Alam Alhaj (1967-1998)

Seripaduka Baginda Tuanku Sultan Azmy Perkasa Alam Shah Alhaj (Medan, 24 April 1936 - Jakarta, 4 Mei 1998) adalah Sultan Deli ke-12 yang memerintah dari tahun 1967 hingga 1998. Sultan Azmy Perkasa Alam menggantikan kedudukan ayahandanya, Sultan Osman Al Sani Perkasa Alam Syah (Sultan Otteman II), sebagai Sultan Deli dan penguasa tertinggi Adat-Istiadat Melayu Deli. Sebagai Sultan Deli, selain berkedudukan sebagai seorang Kepala Adat ia juga turut aktif sebagai unsur dalam berbagai organisasi sosial, pendidikan, dan budaya. Ia juga duduk sebagai anggota DPR/MPR RI[3] selama dua priode, serta sebagai salah seorang pendiri Universitas Amir Hamzah, Deli Serdang. Sultan Azmi Perkasa Alam mangkat di Jakarta pada tanggal 4 Mei 1998 pada usia 62 tahun, dan dimakamkan di Komplek Pemakaman Sultan di areal Masjid Raya Al-Mashun Medan.

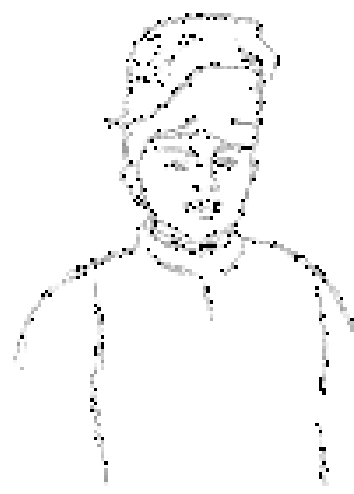

Gambar 11. Sultan ke XI : Sultan Azmy Perkasa Alam Alhaj (1967-1998)

12. Sultan Otteman Mahmud Perkasa Alam (1998-2005)

Sultan Osman Al Sani Perkasa Alamsyah merupakan seorang anggota TNI yang berpangkat Letnan Kolonel (Infantri). Sultan Otteman Mahmud Perkasa Alam diangkat menjadi Raja Kesultanan Deli yang Ke XII pada tahun 1998. Sultan Otteman Mahmud Perkasa Alam tidak bisa melakukan dan memimpin sepenuhnya dalam pelaksanaan acara adat yang ada di Kesultanan Deli karena beban tugasnya sebagai anggota TNI.

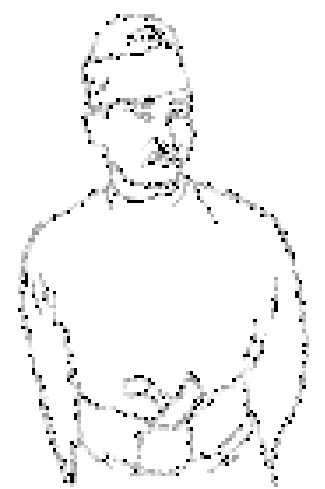

Gambar 12. Sultan ke XII : Sultan Otteman Mahmud Perkasa Alam (1998-2005)

13. Sultan Mahmud Lamanjiji Perkasa Alam (2005-Sekarang)

Seripaduka Baginda Tuanku Sultan Mahmud Arya Lamanjiji Perkasa Alam Shah atau cukup disingkat Tuanku Aji (lahir di Makassar, Sulawesi Selatan, 17 Agustus 1997; umur 22 tahun) adalah Sultan Deli ke-14 yang naik tahta sejak 23 Juli 2005[3]. Dia 
adalah Sultan Deli termuda dalam sejarah. Sultan termuda sebelumnya adalah Sultan Ma'moen Al Rasyid Perkasa Alam Shah (1873-1924) yang diangkat menjadi sultan saat berusia 15 tahun. Saat diangkat menjadi sultan, Lamanjiji sedang bersekolah di sebuah SD di Jawa Barat. Kini ia sedang menempuh pendidikan tinggi di Universitas Diponegoro Semarang[4]. Untuk sementara waktu tampuk kepemimpinan Kesultanan Deli dijabat oleh paman Sultan Otteman III Mahmud Ma'amun Padrap Perkasa Alam Shah, Tengku Hamdy Osman Deli Khan Alhaj bergelar Tengku Raja Muda Deli.

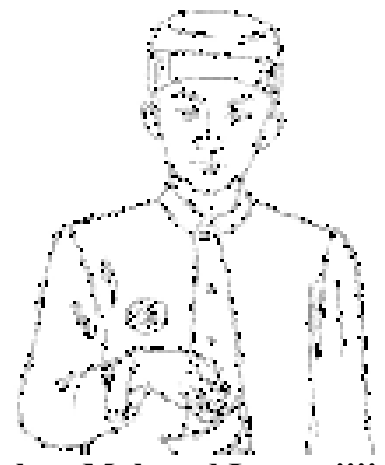

Gambar 13. Sultan ke XIII : Sultan Mahmud Lamanjiji Perkasa Alam (2005-Sekarang)

\section{KESIMPULAN}

Informasi mempermudah setiap kegiatan atau aktifitas sehingga menjadi petunjuk yang bisa menjelaskan suatu benda atau tempat. Buku Informasi panduan wisata sejarah adalah salah satu faktor yang mendukung perkembangan pariwisata. Informasi mengenai generasi Sultan yang pernah memerintah di Kesultanan Deli saat ini masih terbatas pada deretan foto yang terletak pada dinding bagian dalam Istana Maimun. Kondisi ini menyebabkan kurang tersampaikannya informasi kepada wisatawan dan masyarakat. Dengan menggunakan media infographic lebih menarik dan kreatif agar dapat menarik minat masyarakat sehingga dapat dijadikan media promosi untuk memperkenalkan sejarah Istana Maimoon.

\section{DAFTAR PUSTAKA}

[1] Ajeng Resnatika, Sukaesih, Nuning Kurniasih (2018). Peran infografis sebagai media promosi dalam pemanfaatan perpustakaan. Jurnal Kajian Informasi \& Perpustakaan Vol. 6, No. 2

[2] Arikunto. S, (2006). Metodelogi Penelitian. Yogyakarta: Bina Aksara.

[3] Dur, B. I. U. (2014). Data Visualization and Infographics in Visual Communication Design Education at The Age Of Information. Journal of Arts and Humanities, 3 (5), 39 .

[4] Inigopatria, Septa. (2014). Indonesia Dalam Infografik. Jakarta: Kompas Rustan. 
[5] Krum, R. (2013). Cool Inforgraphics : Effective Communication With Data Visualization and Design. John Wiley \& Sons.

[6] Lankow, Jason., Ritchie, Josh., Crooks, Ross. (2014). Infografis : Kedahsyatan Cara Bercerita Visual. Jakarta : PT Gramedia Pustaka Utama.

[7] Moleong, (2005). Metodologi Kualitatif Edisi Revisi. Bandung: PT Remaja Rosdakarya.

[8] Moleong, Lexy J. (2007) Metodologi Penelitian Kualitatif, Penerbit PT Remaja RosdakaryaOffset, Bandung

[9] Nazir. 1998. Metode Penelitian. Jakarta : Rineka Cipta.

[10] Prasetya, A. Setiawan. (2017) . Perancangan Buku infografis kompleks masjid Gedhe Mataram Kotagede. Skripsi thesis, Institut Seni Indonesia Yogyakarta.

[11] Smiciklas, M. (2012). The Power Of Infographics. Indiana polis: Pearson Education, Inc.

[12] Supardi. M.d, (2006). Metodologi Penelitian. Mataram : Yayasan Cerdas Press. 